\title{
Impact of Serum Interleukin 6 among Helicobacter Pylori- Positive Adult Patients in Relation to upper gastrointestinal endoscopy findings
}

\author{
Seham A. Omar' Mohamed F. Hassan², and Basma B. Hasan ${ }^{3^{*}}$ \\ 'Department of Internal Medicine, '2Department of Endemic and Infectious Diseases, Faculty of Medicine, Suez \\ Canal University, 3Department of Clinical Pathology, Faculty of Medicine, Port Said University, Egypt
}

\begin{abstract}
Background: Helicobacter pylori (H. pylori) is one of the most common chronic bacterial infections in humans and has a major etiologic role for several gastroduodenal diseases. Interleukin6 (IL-6) is a multifunctional cytokine and H. Pylori may stimulate its production. Aim: to assess the serum level of IL- 6 in $\mathrm{H}$. pylori infected patients and to study its relation to gastric endoscopy findings. Subjects and Patients and Methods: Eighty-four participants were enrolled; 42 patients with positive H. pylori (patient group "B"), and 42 age and gender-matched subjects with negative $\mathrm{H}$. pylori (control group " $A$ "). Out of 42 patients in the group $B, 21$ patients were subjected to upper gastrointestinal endoscopy due to persistent gastric upset. Serum concentration of IL- 6 was measured in all subjects by ELISA. Results: serum IL- 6 was significantly higher in patients' group compared to control group $(4.3 \pm 0.7 \mathrm{vs} 1.5 \pm 0.3 \mathrm{pg} / \mathrm{ml}, p<0.05)$. The prevalence of IL-6 in infected patient with H. Pylori was 92\%, with highest levels in those with gastric ulcer. Conclusion: $\mathrm{H}$. Pylori infection is associated with high serum level of IL- 6 especially in those with gastric ulcer.
\end{abstract}

Keywords: Helicobacter pylori; interleukin 6

\section{Introduction}

Helicobacter pylori ( $H$. pylori) is one of the most common chronic bacterial infections in humans. It occurs throughout the world and has a major etiologic role for several gastroduodenal diseases, including gastric ulcer, duodenal ulcer, gastric mucosa associated lymphoid tissue lymphoma, and gastric carcinoma ${ }^{(1)}$. H. pylori currently infects more than $50 \%$ of the world's populations, and in the last decade, it has been recognized as one of the most common chronic bacterial infections worldwide(2). Evidences for effectiveness gained from randomized controlled trials suggested that treating $H$. pylori is more effective and less expensive than continuous use of proton pump inhibitor therapy(3), significantly reduced peptic ulcer diseases and improved dyspeptic symptoms and quality of life $\mathrm{e}^{(4,5)}$. $\mathrm{H}$. pylori infection induces an inflamma- 
tory response that is also oxidative, induces chronic active inflammation with a mixture of neutrophils, plasma cells, T-cells and B-cells with production of interleukins $(1,2,6,8)$, tumor necrosis factor (TNFa) and interferon $\gamma(\text { IFN- } \gamma)^{(6)}$. Interleukin-6 (IL-6) is a multifunctional cytokine (26 kDa glycoprotein) that is produced by many different types of cells, including monocytes, lymphocytes, fibroblasts, endothelial cells, keratinocytes, mesangial cells, and endometrial cells $(7)$. The current study was conducted to look up and evaluate the level of serum IL-6 in $H$. pylori infected patients and to assess its relation to gastric endoscopy findings.

\section{Subjects and Methods}

This cross-sectional descriptive study was conducted in the outpatient clinic and gastrointestinal endoscopy unit of the Suez Canal University hospitals on 84 patients (group “B”). All individuals were tested for $H$. Pylori fecal antigen and 42/84 patients tested positive $\mathrm{H}$. pylori stool antigen (confirmed by rapid urease test). Similar number of age and gendermatched healthy persons with negative $\mathrm{H}$. pylori served as control group "A". Out of 42 patients in the group $B, 21$ patients underwent upper gastrointestinal endoscopy due to persistent gastric upset.

\section{Assessment of serum IL-6}

Serum concentration of IL- 6 was measured by commercial enzyme-linked immunosorbent assay (ELISA) kit (Abcam IL6 Human ELISA Kit ab100572). IL-6 Human ELISA kit is an in vitro assay for the quantitative measurement of Human IL-6 in serum, plasma, and cell culture supernatants. This assay employs an antibody specific for Human IL-6 coated on a 96well plate. Standards and samples were pipette into the wells and IL-6 present in a sample was bound to the wells by the immobilized antibody. The wells were washed, and biotinylated anti-Human IL- 6 antibody was added. After washing away unbound biotinylated antibody, HRPconjugated streptavidin was pipetted to the wells. The wells were again washed, a TMB substrate solution was added to the wells and colour developed in proportion to the amount of IL- 6 bound. The stop solution changed the colour from blue to yellow, and the intensity of the colour was measured at $450 \mathrm{~nm}$; the detection limit of the ELISA kit for IL 6 is above $2 \mathrm{pg} / \mathrm{ml}$.

\section{Ethical Considerations}

The study was approved by the SCU Ethical Committee, patients had their information sheet exploring the purpose, methods, effects, and possible value and complications of this research. A written informed consent was obtained from all participants. who was assured about the confidentiality of their information.

\section{Results}

Eighty-four subjects, 57\% were males and were $43 \%$ females. The age of our subjects range 19-59 years old with mean age was $37.54 \pm 10.19$ years old. $54.76 \%$ of $\mathrm{H}$. Pylori infected patients were male while $45.23 \%$ of them were female. About $61.9 \%$ of $\mathrm{H}$. Pylori infected patients were living in rural areas and $38.09 \%$ of them were living in urban areas as shown in (table 1). The mean serum level of IL- 6 were significantly higher in $\mathrm{H}$. Pylori infected group $(4.3 \pm 0.7)$ than in healthy control group $(1.5 \pm 0.3) \quad(p<0.05)$, (table $2)$. The highest level of serum IL-6 in group B was $5.8 \mathrm{pg} / \mathrm{ml}$, and the highest level of serum IL- 6 in group A was $2 \mathrm{pg} / \mathrm{ml}$. the lowest level of serum IL- 6 was $3.1 \mathrm{pg} / \mathrm{ml}$ (in group B) and $1 \mathrm{pg} / \mathrm{ml}$ 
(in group A). The highest of serum interleukin 6 was observed in patients with gastric ulcer $(5.8 \mathrm{pg} / \mathrm{ml})$ (table 2$)$.
Overall, the prevalence of IL-6 in infected patient with $\mathrm{H}$. Pylori was $92 \%$ (table 3).

Table 1: The relation between $\mathrm{H}$. Pylori infection and gender

\begin{tabular}{|c|c|c|c|}
\hline \multirow{2}{*}{ Group } & \multicolumn{2}{|c|}{ Gender } & \multirow{2}{*}{ Total } \\
\cline { 2 - 3 } & $\begin{array}{c}\text { Male } \\
\text { No. (\%) }\end{array}$ & $\begin{array}{c}\text { Female } \\
\text { No. }(\%)\end{array}$ & \\
\hline Study (B) & $23(54.76 \%)$ & $19(45.23 \%)$ & $42(100 \%)$ \\
\hline
\end{tabular}

\section{Discussion}

Regarding the gender, Current data showed that $\mathrm{H}$. Pylori Positivity had predominance in males $(54.76 \%)$ compared to females (45.23\%); the results which in agreement with other previous records. Woodward et al, Kaore et al., valliani et al., reported that higher prevalence of $\mathrm{H}$. pylori in male gender(8-10). In addition, more comprehensive meta-analysis of large population-based studies concluded a male predominance of $\mathrm{H}$. Pylori related diseases. In contrast, Zhu et al, reported that female had a higher $\mathrm{H}$.
Pylori infection rate than male ${ }^{(11)}$. The explanation for this difference can only speculative at this moment, being most probably related to the hormonal differences between the two genders, as recent studies identified an important role of oxytocin in the gastric evacuation rate ${ }^{(12)}$. The present study showed that $\mathrm{H}$. pylori infected patients had a higher concentration of serum IL-6. Other study reported the same result; Hiroko et al reported that higher $\mathrm{H}$. pylori lgG levels were significantly associated with higher serum IL- 6 levels among $H$. pylori-infected individuals(7).

Table 2: Serum IL-6 (pg/ml) level in study populations

\begin{tabular}{|c|c|c|c|c|c|c|}
\hline \multirow{3}{*}{ 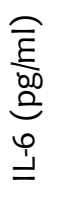 } & Group & $\begin{array}{c}\text { Highest } \\
\text { Level }\end{array}$ & $\begin{array}{c}\text { Lowest } \\
\text { level }\end{array}$ & Mean & SD & $\begin{array}{l}\text { P value } \\
\text { (T-test) }\end{array}$ \\
\hline & Control (Group A) & 2 & 1 & 1.595 & 0.3561 & \multirow{2}{*}{$0.000 *$} \\
\hline & Patients (Group B) & 5.8 & 3.1 & 4.329 & 0.7286 & \\
\hline
\end{tabular}

Similarly, Siregar et al, reported that Serum IL-6 level was significantly higher in $\mathrm{H}$. Pylori positive group compared to $\mathrm{H}$. pylori negative group in a study which had done at 80 patients admitted to endoscopy units at Adam Malik General Hospital and Permata Bunda Hospital, Medan, Indonesia from May-October 2014(13). In addition, Yamaoka et al, showed that mucosal IL-6 levels were higher in early gastric cancer with active $\mathrm{H}$. pylori infection than without $\mathrm{H}$. pylori infection(14). Moreover, Azadegan Dehkordi et al, reported that the mucosal IL6 mRNA level increased in patients with $H$. pylori infection compared with uninfected patients and correlated positively with the grade of chronic gastritis in patients with $H$. pylori infection (15). However, Bayraktaroglu et al could not detect statistically significant differences in the serum levels of IL-6, IL- 8 and TNF- $\alpha$ 
with respect to the presence or absence of $\mathrm{H}$. pylori determined by Giemsa staining of gastric tissues ${ }^{(16)}$. Also, Akgun et al., reported that serum levels of IL-8 did not differ between $\mathrm{H}$. Pylori infected and uninfected persons, this finding may indicate that this infection remains local without inducing systemic inflammation(17). Regarding another associated multifunctional cytokine (IL-8), Fan et al., found that IL-8 concentrations in gastric juice and biopsy homogenate supernatant fluid were increased in patients with $\mathrm{H}$. Pylori infection compared with the patients without infection, but this difference was not observed for plasma IL-8 concentration $^{(18)}$. As well, Audibert et al.(19) and Crabtree et al.(20), acknowledged that there is an increased mucosal production of IL-8 that may be an important mediator of the inflammatory response. They also confirmed the finding that CagA positive $\mathrm{H}$. Pylori strains induce significantly higher levels of IL6 and IL- 8 on Hep-2 cell cultures than CagA negative strains.

Table 3: Serum level of IL-6 and result of gastric Endoscopy

\begin{tabular}{|c|c|c|c|c|c|}
\hline \multirow{2}{*}{$\begin{array}{c}\text { Endoscopy } \\
\text { Findings (n=21) }\end{array}$} & $\begin{array}{c}\text { Normal } \\
\text { No (\%) }\end{array}$ & $\begin{array}{c}\text { Erosive gastritis } \\
\text { No (\%) }\end{array}$ & $\begin{array}{c}\text { Atrophic gastritis } \\
\text { No (\%) }\end{array}$ & $\begin{array}{c}\text { Gastric ulcer } \\
\text { No (\%) }\end{array}$ & P* \\
\cline { 2 - 5 } & $8(38.1 \%)$ & $4(19.1 \%)$ & $4(19.1 \%)$ & $5(23.7 \%)$ & \multirow{2}{*}{0.000} \\
\hline $\begin{array}{c}\text { IL 6 (pg/ml) } \\
\text { (highest level) }\end{array}$ & 3.1 & 4.4 & 3.5 & 5.8 & \\
\hline
\end{tabular}

*T-test

As a final point, up to date studies have shown that $H$. pylori activates signal transducer and activator of transcription 3 (STAT3) that plays an imperative role in gastric carcinogenesis. Yet, the molecular mechanism underlying $\mathrm{H}$. pylori-mediated STAT3 activation is still not fully unstated. Riao et al., recognized that, $\mathrm{H}$. pyloriinduced STAT3 activation is mediated, at least in part, through reactive oxygen species-induced up regulation of IL- 6 expression $^{(21)}$. These results provide a novel molecular mechanism accountable for $\mathrm{H}$. pylori-induced gastritis and gastric carcinogenesis. The main limitation of the study was the sample size. A wider study is required with reassessment of IL- 6 levels after eradication of $\mathrm{H}$. pylori and to evaluate its prognostic values.

\section{Conclusion}

Serum IL-6 is significantly higher in $\mathrm{H}$. Pylori infected patients and the highest levels were observed in patients with gastric ulcer than in those with erosive or atrophic gastritis.

Funding: None

Conflicts of interest: None

\section{References}

1. Siavoshi F, Malekzadeh R, Daneshmand $M$, et al. (2005): Helicobacter pylori endemic and gastric disease. Dig Dis Sci 2005; 50:2075-80.

2. Sugimoto $M$, Zali $M R$ and Yamaoka $Y$, et al (2009): The association of vac $A$ genotypes and Helicobacter pylori related gastroduodenal diseases in the Middle East. Eur J Clin Microbiol Infect Dis 2009, 28(10): 1227-1236.

3. Salih BA, (2009): Helicobacter pylori infection in developing countries: The burden for how long? Saudi Journal of gastroenterology.2009; 15(3):201-207.

4. Farkkila M, Sarna S, Valtonen VV, Sipponen P (2004): PROSPER study group. Does the test and treat strategy work in primary health care for 
management of uninvestigated dyspepsia? Scand J gastroenterol. 2004:39:372-35.

5. Mason J, Axon AT, Forman D, et al (2002): The cost effectiveness of population Helicobacter Pylori screening and treatment .2002;16:559-68.

6. Karttunen R, Karttunen T, Ekre HP, MacDonald TT (1995): Interferon gamma and interleukin 4 secreting cells in the gastric antrum in Helicobacter pylori positive and negative gastritis. Gut. 1995; 36:341-5.

7. Hiroko N, Takashi T, Yoko $M$, et al. (2013): Significant Association between Serum Interleukin-6 and Helicobacter pylori Antibody Levels among $\mathrm{H}$. Pylori-Positive Japanese Adults, Mediators of Inflammation, Volume 2013, Article ID 142358.

8. Woodward M, Morrison C and McColl $\mathrm{K},(2000)$ : An investigation into factors associated with Helicobacter pylori infection. J Clin Epidemiol 2000, 53:175181.

9. Kaore NM, Nagdeo NV and Thombare VR. (2012): Comparative evaluation of the diagnostic tests for Helicobacter pylori and dietary influence for its acquisition in dyspeptic patients: A rural hospital based study in central India. JCDR. 6:636-41.

10. Valliani, A., Khan, F., Chagani, B. et al., (2013): Factors Associated with Helicobacter pylori Infection, Results from a Developing Country-Pakistan. Asian Pacific Journal of Cancer Prevention. 14:53-56.

11. De Martel C and Parsonnet J (2006): Helicobacter pylori infection and gender: a meta-analysis of populationbased prevalence surveys. Dig Dis Sci. 51:2292-2301.

12. Zhu $Y$, Xiaoying $Z$, Junbei $W$ et al., (2014): Risk Factors and Prevalence of Helicobacter pylori Infection in Persistent High Incidence Area of Gastric Carcinoma in Yangzhong City. Gastroenterol Res Pract Volume 2014 (2014), Article ID 481365, 10 pages.
13. Siregar GA, Halim S, Sitepu RR (2014): Comparison of IL-6, IL-8 Concentrations in $\mathrm{H}$. pylori- and non- $\mathrm{H}$. Pyloriassociated Gastritis. Indones Biomed J. 2014; 6(3): 163-6.

14. Yamaoka Y, Kodama T, Kita M, Imanishi J, Kashima K, Graham DY, (2001): Relation between cytokines and Helicobacter pylori in gastric cancer. Helicobacter 2001; 6: 116-24.

15. Azadegan-Dehkordi F, Bagheri N, Shirzad M, et al (2015): Correlation Between Mucosal IL-6 mRNA Expression Level and Virulence Factors of Helicobacter pylori in Iranian Adult Patients with Chronic Gastritis (2015). Jundishapur J Microbiol. 2015 August; 8(8): e21701.

16. Bayraktaroglu T, Aras AS, Aydemir S, et al. (2004): Serum level of TNFa, IL 6 , and IL 8 are not increasing in dyspeptic patients with $\mathrm{H}$. Pylori associated gastritis. Mediators inflammation 13(1):25-28.

17. Akgun $\mathrm{Y}$, Kasifoglu $\mathrm{N}$, Saricam $T$, Kiremitci A, Tercan US (2009): IL-8 serum levels in patients with helicobacter Pylori infection and relation between serological markers. Afr J Microbiol Res 3(11): 822-825.

18. Fan XG, Ghua A, Fan XJ, Keeling PWN (1995): increased gastric production of IL-8 and TNF in patients with H. Pylori infection. J. Clin.Pathol.48:133-136.

19. Audibert C, Janvier B, Grignon B, et al (2000): correlation between IL 8 induction, Cag A status and VAC A genotypes in 153 French $\mathrm{H}$. Pylori isolates. Res Microbiol.151(3):191-200.

20. Crabtree JE, Xiang Z, Lindley J, et al (1995): Induction of IL 8 secretion from gastric epith. cells by Cag A negative isogenic mutant of $\mathrm{H}$. Pylori. Clin.Pathol.48:967-969.

21. Piao JY, Lee HG, Kim SJ, et al. Helicobacter pylori Activates IL-6STAT3 Signaling in Human Gastric Cancer Cells: Potential Roles for reactive Oxygen Species. Helicobacter. 2016 Oct; 21(5):405-16. 